\title{
Penjernih Kabut Asap Kebakaran Hutan dengan Media Plasma dan Karbon Aktif Terintegrasi
}

(Smoke Haze Cleaning Using Integrated Plasma and Activated Carbon)

\author{
MUHAMMAD ISNAN, AINUR ROFIQ, IBNU AWAL HASANUDIN DAN THOHARUDIN
}

\begin{abstract}
Smoke haze from forest fires consists of Volatile Organic Compounds (VOC) and particulate matter which has micro size that can cause the respiratory disorders. Therefore, the device to reduce the matters is necessary to prevent the respiratory health including the lung. One of the many methods is using plasma and activated carbon for eliminating the matters from the air that was conducted in this study. Smoke haze was modeled as exhaust gas obtained from rice husk combustion. The velocity of gas in the cleaning device was controlled in various velocities, namely $0.3,0.9,1.2$ and $1.5 \mathrm{~m} / \mathrm{s}$. The calculation of smoke haze particulate matter and VOC was conducted in a simple method by using cutton as filter media to separate the particulate matter and VOC from the gas. This study resulted that the increasing of velocity affected the increasing of particulate matter and VOC filtered on the cutton. The plasma utilisation on the device affected the reduction of particulate matter and VOC filtered on the cutton. The application of both plasma and activated carbon in the device could achieve the best performance of eliminating the particulate matter and VOC indicated by the clean cutton obtained after filtering. The highest efficiency of particulate matter and VOC removal was achieved by applicating both plasma and activated carbon with gas velocity of $1.5 \mathrm{~m} / \mathrm{s}$, namely $96.1 \%$.
\end{abstract}

Keywords: Smoke haze, plasma, activated carbon

\section{PENDAHULUAN}

Kebakaran hutan sering terjadi di beberapa wilayah di Indonesia. Tercatat, kebakaran hutan terparah dekade ini terjadi pada Juli hingga Oktober 2015 yang melahap jutaan hektar hutan dan diperkirakan kerugian negara mencapai $\mathrm{Rp}$ 196 Triliun (Porter, 2016). Di samping dampak ekonomi, kebakaran hutan juga mengakibatkan beberapa penyakit, antara lain ISPA, Asma dan Bronchitis yang diakibatkan oleh tebalnya kabut asap yang mengandung Volatile Organic Compounds (VOC) dan materi partikulat berukuran mikro (Suryani, 2012). Kebakaran hutan memang perlu dihindari, namun bencana alam tersebut perlu untuk diantisipasi dampakdampaknya, terutama dampak kesehatan. Oleh karena itu, perlu dikembangkan alat yang mampu mereduksi VOC dan materi partikulat. VOC yang mampu terkondensasi pada temperatur ruang disebut dengan tar. Tar terdiri atas senyawa-senyawa golongan hidrokarbon dan oxygenated compounds seperti Benzene, Naphthalene, Acetic acid, Phenol dll.
Beberapa penelitian telah dikembangkan untuk mereduksi VOC dan materi partukulat. Sidheswaran dkk (2012) telah mengembangkan serat karbon aktif sebagai media pereduksi VOC hingga 60\%-80\%. Gregorio dkk (2016) telah mampu mereduksi Naphthalene menggunakan karbon aktif dengan efisiensi sangat tinggi. Naphthalene merupakan salah satu senyawa VOC yang tergolong dalam Polycyclic Aromatic Hydrocarbon (PAH), salah satu zat karsinogen penyebab kanker (Haryono dkk, 2016). Selain mereduksi VOC karbon aktif juga mampu untuk menjerap gas Carbon monoksida (Mohamad dkk, 2000) dan karbon dioksida (Zulkurnai dkk, 2017).

Selain karbon aktif, plasma juga telah dikembangkan untuk pereduksi materi partikulat. Kim dkk (2012) mengembangkan plasma yang digabung dengan katalis sebagai pembersih udara. Kuroki dkk (2017) telah mengaplikasikan plasma sebagai media pereduksi partikel berukuran nano pada aliran gas. Poškas dkk (2018) telah mengembangkan plasma sebagai pereduksi materi partikulat. Secara umum, plasma bekerja dengan 
menaikkan temperatur gas dan membangkitkan spesies aktif seperti ion, radikal, dan elektron melalui tumbukan antara molekul gas dan elektron teremisi (Thoharudin dkk, 2011). Oleh karena itu, dengan adanya plasma maka partikel yang ukuran mikro mampu terionisasi menjadi struktur yang lebih ringan atau gas.

Makalah ini menyajikan studi tentang pemanfaatan plasma dan karbon aktif yang terintegrasi sebagai media pereduksi kabut asap hasil dari pembakaran biomassa. Biomass merupakan model dari material yang terbakar saat terjadi kebakaran hutan. Berdasarkan uraian di atas, studi ini bertujuan untuk menganalsis unjuk kerja dari plasma dan karbon aktif terintegrasi sebagai pereduksi materi partikulat dan VOC.

\section{Metode Penelitian}

Asap kabakaran dimodelkan dengan asap hasil pembakaran sekam padi pada ruang bakar yang tersambung dengan alat pereduksi kabut asap seperti terlihat pada Gambar 1. Udara pembakaran sekam padi diatur agar asap yang terbentuk tebal namun tidak tergasifikasi agar gas dan asap yang terbentuk dari pembakaran tersebut tidak dapat terbakar dengan cara mengatur Equivalence Ratio ( $\phi)$ mendekati 1. Equivalence Ratio merupakan pembagian antara Air Fuel Ratio aktual $\left(\mathrm{AFR}_{\mathrm{a}}\right)$ dibagi dengan Air Fuel Ratio stoikiometri $\left(\mathrm{AFR}_{\mathrm{s}}\right)$ seperti terlihat pada persamaan 1 .

$\Phi=\frac{A F R_{a}}{A F R_{s}}$

Sekam padi merupakan limbah sisa padi yang berupa kulit luar biji padi yang diperoleh dari penggilingan guna memisahkan antara padi dengan kulitnya. Sekam padi memiliki berat sekitar 20\% dari berat padi. Ditinjau dari komposisi kimianya melalui analisis proximate dan ultimate, sekam padi memiliki nilai kalor sebesar 14,2 MJ/kg yang dapat dilihat pada Tabel 1.

Melalui analisis Tabel 1, dengan mengubah fraksi massa menjadi fraksi mol, persamaan pembakaran sempurna sekam padi dapat ditampilkan pada persamaan 2 .

$$
\begin{aligned}
& \mathrm{CH}_{1.4} \mathrm{O}_{0.67}+1.35\left(\mathrm{O}_{2}+3.76 \mathrm{~N}_{2}\right) \rightarrow \\
& \mathrm{CO}_{2}+0.7 \mathrm{H}_{2} \mathrm{O}+5.076 \mathrm{~N}_{2}
\end{aligned}
$$

Melalui persamaan 2 dan pengubahan satuan molar menjadi satuan massa, AFR stoikiometri sekam padi dapat ditentukan, yaitu sebesar 7,68 .

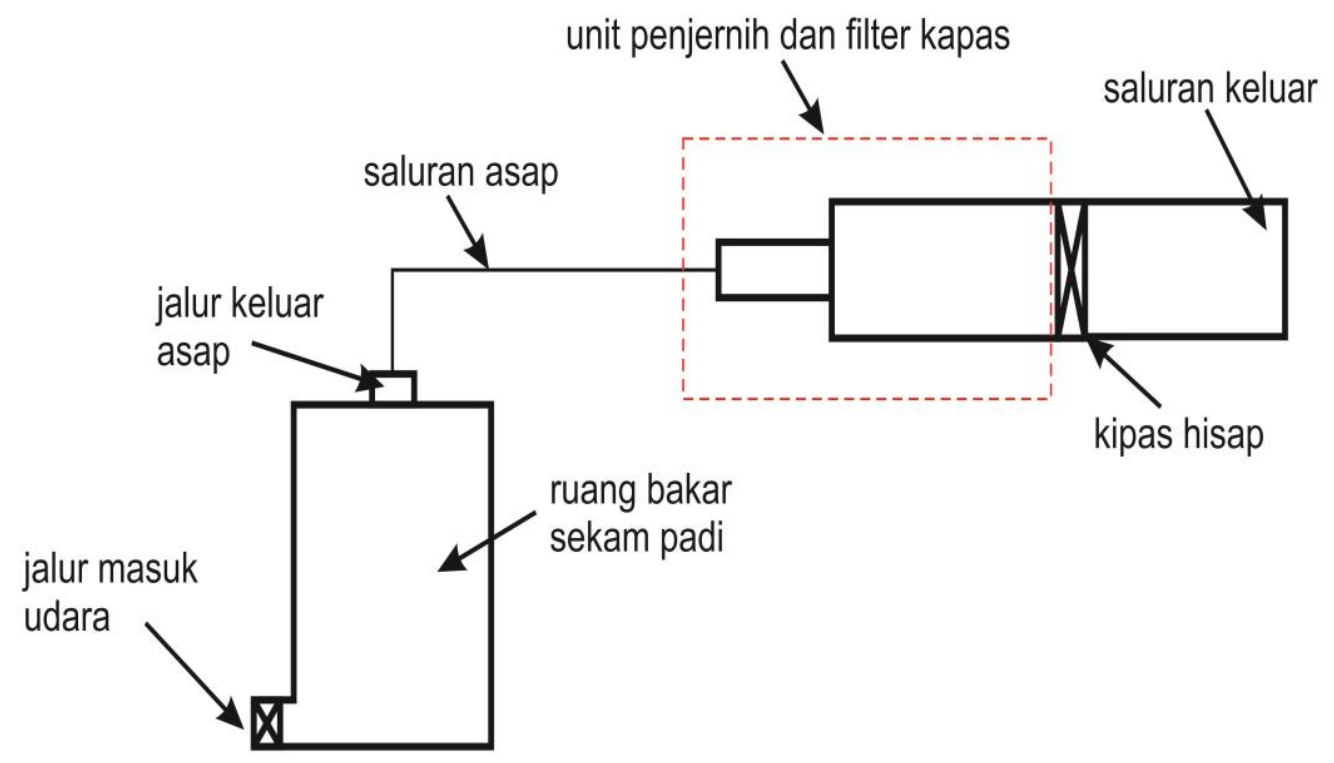

GAMBAR 1. Skema pengujian alat penjernih kabut asap 
TABEL 1. Analisis proximate dan ultimate sekam padi (Jangsawang dkk, 2007)

\begin{tabular}{cc}
\hline \multicolumn{2}{c}{ Proximate analysis (\%dry) } \\
\hline Volatile matter \\
Fixed Carbon & 64,19 \\
Abu & 21,46 \\
\multicolumn{2}{c}{ Ultimate analysis (\%dry) } \\
\hline $\mathrm{C}$ & 14,38 \\
$\mathrm{H}$ & 42,54 \\
$\mathrm{O}$ & 4,99 \\
$\mathrm{~N}$ & 37,75 \\
$\mathrm{~S}$ & 0,2 \\
$\mathrm{Cl}$ & 0,04 \\
\hline Kadar air $(\%)$ & 0,1 \\
\hline LHV $(\mathrm{MJ} / \mathrm{kg})$ & 8,2 \\
\hline
\end{tabular}

Pengujian reduksi kabut asap dilakukan dengan cara pemanfaatan karbon aktif dan plasma. Pengukuran jumlah kabut asap dilakukan dengan cara sederhana, yaitu dengan pemanfaatan media kapas sebagai filter. Artinya, semakin rendah kabut asap yang tertinggal pada kapas mengindikasikan semakin besar kabut asap yang terjernihkan pada alat penjernih kabut asap. Kecepatan hisap kabut divariasikan menjadi empat kecepatan, yaitu $0,3,0,9,1,2,1,5 \mathrm{~m} / \mathrm{dt}$, yang diukur pada saluran keluar. Pengujian dilakukan selama 60 detik tiap variasinya.

Konsentrasi kabut asap/aerosol $\left(\mathrm{m}_{\mathrm{kb}}\right)$ dihitung dengan selisih massa kapas akhir $\left(\mathrm{m}_{2}\right)$ dan awal $\left(\mathrm{m}_{1}\right)$ dibagi dengan volume asap $\left(\mathrm{V}_{\mathrm{a}}\right)$ yang dihisap melalui fan, seperti terlihat pada persamaan 3. Sementara itu, volume asap $\left(\mathrm{V}_{\mathrm{a}}\right)$ dihitung dengan persamaan 4 , di mana $\mathrm{V}_{\mathrm{g}}$ adalah kecepatan asap $(\mathrm{m} / \mathrm{dt}), \mathrm{A}_{\mathrm{c}}$ adalah luas penampang pengukuran kecepatan $\left(\mathrm{m}^{2}\right)$ dan $\mathrm{t}$ adalah waktu pengujian (dt).

$$
\begin{aligned}
& m_{k b}=\frac{m_{2}-m_{1}}{V_{a}} \\
& V_{a}=V_{g} \times A_{c} \times t
\end{aligned}
$$

Efisiensi penjernihan kabut asap/aerosol $\left(\eta_{\mathrm{pk}}\right)$ dapat dihitung dengan persamaan 5 , di mana $\mathrm{m}_{\mathrm{kb1}}$ merupakan massa kabut asap tanpa proses penjernihan, $\mathrm{m}_{\mathrm{kb} 2}$ merupakan massa kabut asap setelah melalui proses penjernihan.

$$
\eta_{p k}=\frac{m_{k b 1}-m_{k b 2}}{m_{k b 1}} \times 100 \%
$$

\section{HASIL DAN PEMBAHASAN}

Proses penjernihan gas diuji dengan tiga parameter, yaitu gas hasil pembakaran sekam padi tanpa proses penjernihan, dengan penjernihan plasma dan penjernihan gabungan antara plasma dan karbon aktif. Penempatan karbon aktif tersebar pada celah-celah rongga kapas. Secara visual, hasil filtrasi mengunakan kapas dapat dilihat pada Gambar 2. Gambar 2 memperlihatkan visual kapas tanpa penjernihan kabut asap, dengan penjernihan plasma dan dengan penjernihan gabungan plasma dan karbon aktif.

Gambar 2 memperlihatkan bahwa kapas filter tanpa melalui penjernihan gas (a) memiliki warna cokelat lebih pekat dibandingkan dengan kapas filter yang dilakui gas pembakaran sekam padi melalui pejernihan plasma (b). Warna kecokelatan tersebut disebabkan oleh materi partikulat dan VOC yang terperangkap dalam permukaan kapas. Oleh karena itu, dengan semakin pekat warna kapas mengindikasikan semakin besar materi partikulat dan VOC yang terfilter pada kapas. VOC yang terkondensasi dan bercampur dengan materi partikulat disebut dengan aerosol, berwarna pekat dan berbau menyengat (Basu, 2013). 


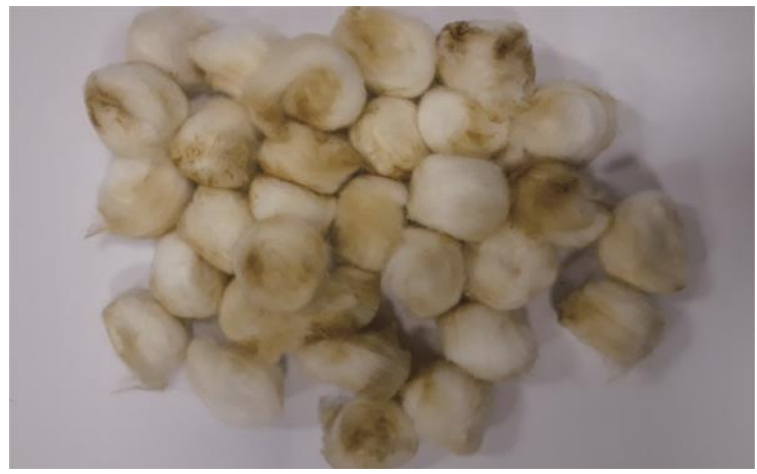

(a)

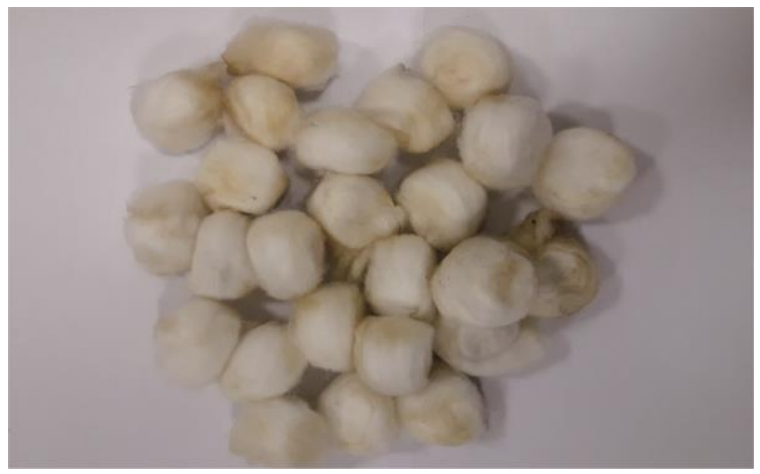

(b)

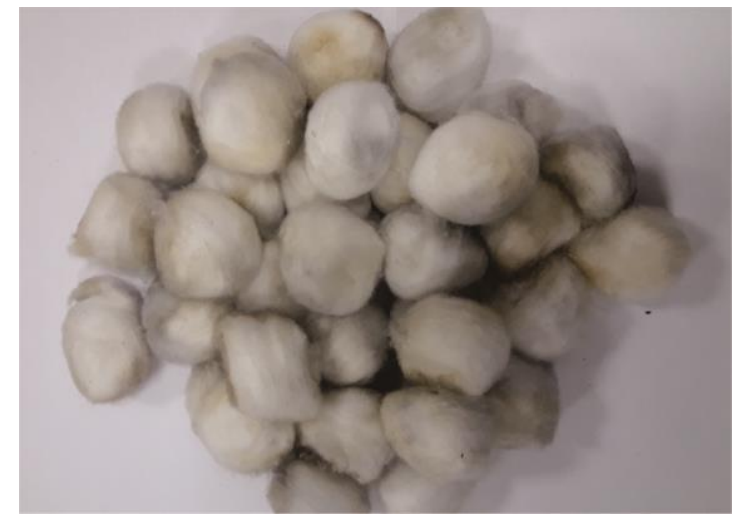

(c)

GAMBAR 2. (a) Kapas tanpa penjernihan kabut asap, (b) kapas dengan penjernihan plasma, (c) kapas dengan penjernihan gabungan plasma dan karbon aktif

Secara visual, kapas filter pada penjernihan gas dengan media gabungan antara plasma dan karbon aktif lebih bersih dari warna kecokelatan dan cenderung putih dan sedikit kehitaman. Warna hitam pada kapas tersebut bukan berasal dari filtrasi materi partikulat dan VOC dari gasbuang pembakaran sekam padi. Namun, warna hitam tersebut karena adanya partikel mikro karbon aktif yang menempel pada permukaan kapas, karena peletakan karbon aktif yang bercampur dengan kapas filter. Massa aerosol yang menempel pada kapas kemudian dihitung dengan persamaan 3 sehingga meghasilkan hubungan antara konsentrasi aerosol terhadap kecepatan gas buang pembakaran sekam padi yang ditampilkan pada Gambar 3. 


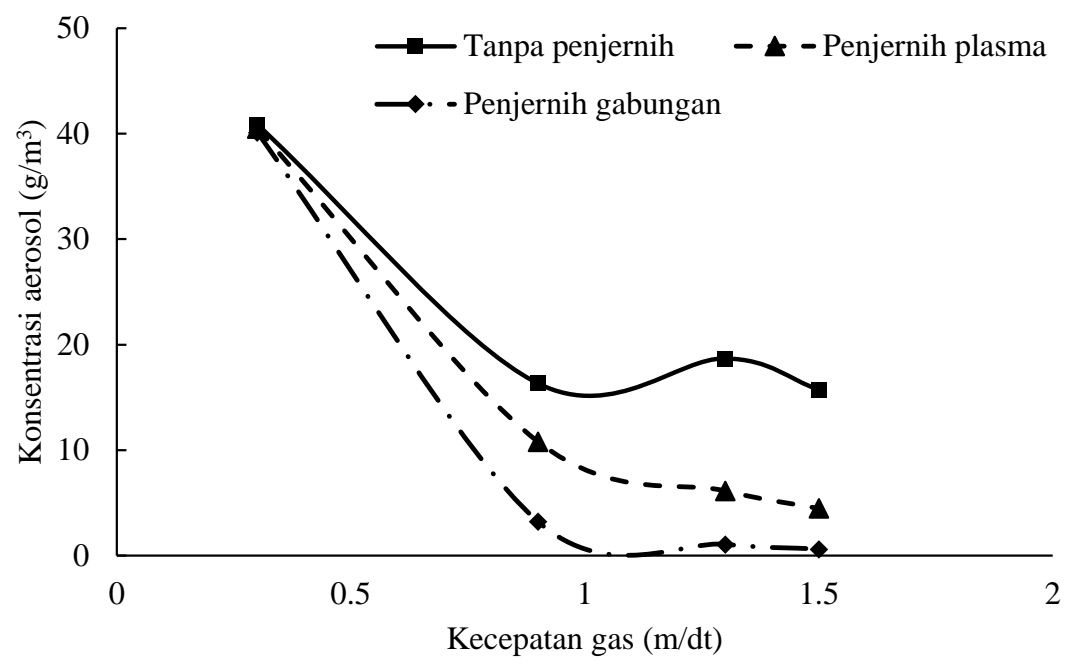

GAMBAR 3. Konsentrasi aerosol terhadap kecepatan gas

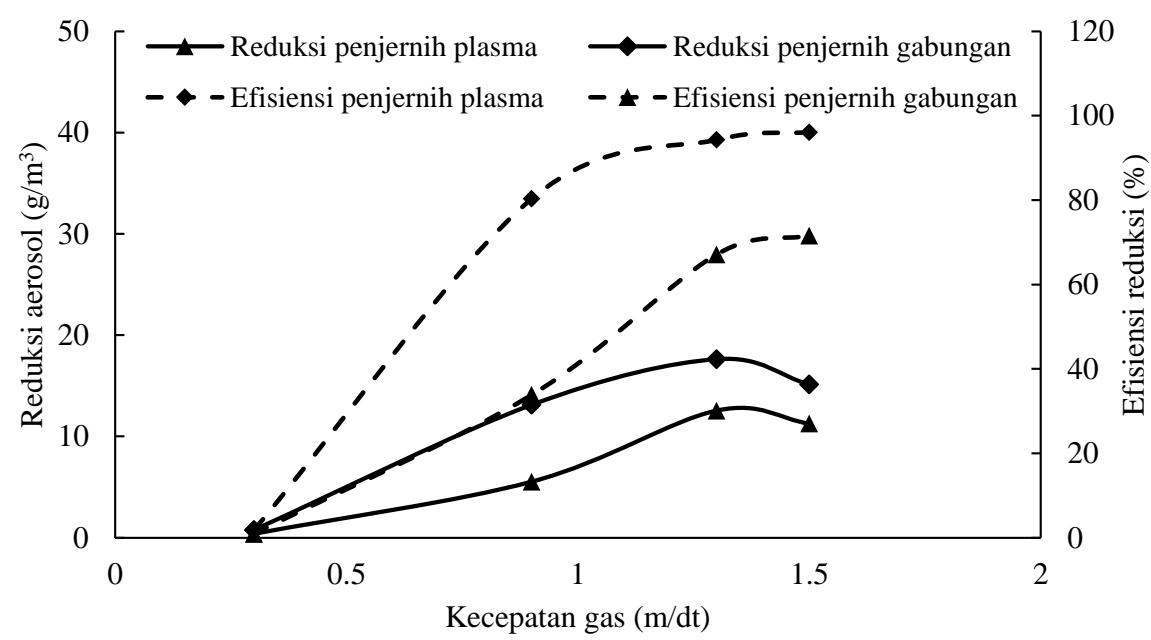

GAMBAR 4. Reduksi aerosol dan efisiensi reduksi terhadap kecepatan gas

Terlihat pada Gambar 3 bahwa dengan semakin besar kecepatan hisap gas maka konsentrasi aerosol semakin rendah, baik pada aliran gas tanpa penjernih maupun dengan penjernih. Hal ini karena dengan semakin besar kecepatan maka fraksi gas yang mengalir lebih banyak dibandingkan dengan fraksi aerosol, sehingga konsentrasi aerosol menurun dengan semakin besarnya kecepatan.

Terlihat pula pada Gambar 3 bahwa pada kecepatan rendah konsentrasi tar baik dengan penjernih maupun tanpa penjerih gas tidak memperlihatkan perbedaan yang signifikan. Namun, dengan semakin besar kecepatan berbedaan konsentrasi antar beberapa perlakuan menampilkan berpedaan yang mencolok. Kecepatan yang rendah berdampak pada timbulnya pola aliran laminar yang berakibat pada rendahnya kontak antara gas mengandung aerosol dengan karbon aktif. Sementara itu, kinerja plasma sebagai media ionisasi gas juga tidak bekerja dengan optimal pada aliran gas yang laminar.

Gambar 4 memperlihatkan hubungan antara reduksi aerosol dan efisiensi reduksi terhadap kecepatan gas. Reduksi aerosol semakin besar dengan semakin besarnya kecepatan hingga mecapai optimum pada kecepatan 1,2 m/dt dan kemudian terjadi penurunan reduksi baik pada penjernihan plasma ataupun dengan gabungan palsma dan karbon aktif. Namun, efisiensi reduksi terus meningkat dengan gradien yang landai pada kecepatan gas melebihi $0,9 \mathrm{~m} / \mathrm{dt}$.

Penurunan reduksi aerosol yang terjadi baik pada penjernihan plasma maupun gabungan 
disebabkan oleh tingginya kecepatan yang mengakibatkan rendahnya kontak antara gas yang mengandung aerosol dan karbon aktif maupun plasma. Plasma bekerja dengan memecah ikatan kimia aerosol melalui mekanisme ionisasi. Oleh karena itu, dengan semakin besar kecepatan maka jumlah aliran gas yang mengandung aerosol semakin besar sehingga energi yang dipancarkan oleh plasma tidak mencukupi untuk memecah semua aerosol yang berakibat pada turunnya reduksi aerosol pada kecepatan gas yang tinggi.

Gambar 4 juga memperlihatkan perbedaan yang signifikan pada reduksi aerosol dan efisiensi reduksi yang terjadi pada penjernihan plasma dan gabungan plasma dan karbon aktif. Tingginya reduksi tar dan efisiensi reduksi pada penjernih gabungan plasma dan karbon aktif disebabkan oleh perpaduan kerja di mana plasma memecah aerosol menjadi molekul yang lebih ringan dan karbon aktif menjerab molekul yang ringan tersebut pada permukaan karbon aktif. Reduksi aerosol dengan penjernih plasma mampu mencapai efisiensi optimum sebesar $71,6 \%$ dengan reduksi aerosol sebesar 11,3 $\mathrm{g} / \mathrm{m}^{3}$. Sementara reduksi aerosol dengan penjernih gabungan plasma dan karbon aktif mampu mencapai efisiensi hingga 96,1\% dengan reduksi aerosol sebesar $15,1 \mathrm{~g} / \mathrm{m}^{3}$.

\section{KESIMPULAN}

Pada studi ini, telah dilakukan pengujian alat penjernih kabut asap kebakaran hutan yang dimodelkan dengan pembakaran biomassa. Alat penjernih tersebut terdiri atas plasma dan kabon aktif yang diuji pada variasi kecepatan 0,3-1,5 $\mathrm{m} / \mathrm{dt}$. Penjernih plasma mampu mereduksi aerosol dengan efisiensi reduksi $71,6 \%$, namun dengan penggabungan antara plasma dan karbon aktif, alat penejernih tersebut mampu mereduksi aerosol hingga efisiensi reduksinya $96,1 \%$. Reduksi aerosol pada penjernih plasma mampu mereduksi $12,6 \mathrm{~g} / \mathrm{m}^{3}$ sementara dengan penggabungan plasma dan karbon aktif mampu mencapai $17,6 \mathrm{~g} / \mathrm{m}^{3}$.

\section{UCAPAN TERIMA KASIH}

Penulis mengucapkan terima kasih atas dukungan pendanaan oleh Kemenristek Dikti melalui Program Kreativitas Mahasiswa skema Karsa Cipta (PKM-KC) sehingga penulis mampu melaksanakan kegiatan dan mempublikasikan hasil karyanya.

\section{DAFTAR PUSTAKA}

Basu, P. (2013). Biomass Gasification, Pyrolysis, and Torrefaction. Practical Design and Theory. Oxford: Elsevier Inc.

Gregorio, F.D., Parrillo, F., Salzano, E., Cammarota, F., \& Arena, U. (2016). Removal of Naphthalene by Activated Carbons from Hot Gas. Chemical Engineering Journal, 291, 244-253.

Haryono, W., Caroko, N., \& Thoharudin. (2016). Pirolisis Lambat Campuran Batubara dan Plastik dengan Katalis Zeolit Alam. Teknoin, 22, 383-390.

Jangsawang, W., Gupta, A., Kitagawa, K., \& Lee, S. (2007). High Temperature Steam and Air Gasification of Non-woody Biomass Wastes. Asian Journal on Energy and Environment, 8, 601-609.

Kim, H., \& Ogata, A. (2012). Interaction of Nonthermal Plasma with Catalyst for the Air Pollution Control. International Journal of Plasma Environmental Science \& Technology, 6, 43-48.

Kuroki, T., Nishii, S., Kuwahara, T., \& Okubo, M. (2017). Nanoparticle Removal and Exhaust Gas Cleaning Using Gas-Liquid Interfacial Nonthermal Plasma. Journal of Electrostatics, 87, 86-92.

Mohamad, A., Iyuke, S., Daud, W., Kadhum, A., Fisal, Z., Al-Khatib, M., \& Shariff, A. (2000). Adsorption of Carbon Monoxide on Activated Carbon-Tin Ligand. Journal of Molecular Structure, 550-551, 511-519.

Porter, S. (2016). BBC. Dipetik 07 12, 2018, dari

https://www.bbc.com/indonesia/berita_in donesia/2016/03/160314_indonesia_keba karan_hutan_2016.

Poškas, R., Sirvydas, A., Jouhara, H., \& Poškas, P. (2018). Investigation of Characteristics of Solid Particles from a Mixture of Sewage Sludge and Wood Pellets 
Synthetic Gas and Their Clean-up. Waste Management, 78, 1-7.

Sidheswaran, M.A., Destaillats, H., Sullivan, D.P., Cohn, S., \& Fisk, W.J. (2012). Energy Efficient Indoor VOC Air Cleaning with Activated Carbon Fiber (ACF) Filters. Building and Environment, 47, 357-367.

Suryani, A.S. (2012). Penanganan Asap Kabut Akibat Kebakaran Hutan di Wilayah Perbatasan Indonesia. Aspirasi, 3, 59-75.

Thoharudin, Nugroho, A.S., Suyitno, \& Wibowo, H.A. (2011). Methane Steam Reforming to Produce High Ratio of Hydrogen to Carbon Monoxide by Using CFD. International Conference and Exhibition on Sustainable Energy and Advanced Materials, Solo, (pp.199-206).

Zulkurnai, N.Z., Ali, U.F.Md., Ibrahim, N., \& Manan, A.N. (2017). Carbon Dioxide $\left(\mathrm{CO}_{2}\right)$ Adsorption by Activated Carbon Functionalized with Deep Eutectic Solvent (DES). IOP Conf. Series: Materials Science and Engineering, 206.
Muhammad Isnan

Program Studi Teknik Mesin, Universitas Muhammadiyah Yogyakarta, D.I. Yogyakarta 55183.

Email:muhammad.isnan.2015@ft.umy.ac.id

Ainur Rofiq

Program Studi Teknik Mesin, Universitas Muhammadiyah Yogyakarta, D.I. Yogyakarta 55183.

Email: ainur.rofiq.2015@ft.umy.ac.id

Ibnu Awal Hasanudin

Program Studi Teknik Mesin, Universitas Muhammadiyah Yogyakarta, D.I. Yogyakarta 55183.

Email: ibnu.awal.2016@ft.umy.ac.id

Thoharudin

Program Studi Teknik Mesin, Universitas Muhammadiyah Yogyakarta, D.I. Yogyakarta 55183.

Email: thoharudin@ft.umy.ac.id 